\title{
Reinstitutionalizing transparency at Health Canada
}

$\mathrm{H}$ ow do you change the way an institution has worked for nearly a century? This is the challenge that the biomedical community must help Health Canada confront if the regulation of pharmaceutical drugs is to substantially improve. Transparency was once characteristic of Canadian pharmaceutical regulation. Recent changes in law may mark a return to openness, but if history is instructive, physicians and biomedical researchers will need to push the regulator for change.

The regulation of pharmaceutical drugs was once a remarkably public exercise. ${ }^{1}$ Starting in 1887 , the Canadian regulator (originally the Department of Inland Revenue) began publishing bulletins. Often hundreds of pages, the bulletins named names, identifying "drug houses" and "shop-keeps" that produced adulterated goods. ${ }^{2}$ From 1887 to 1920 , 440 bulletins were disseminated, engaging news media, physicians, pharmacists and regulatory scientists, resulting in the creation and improvement of standards of drug preparation.

When the new federal Department of Health took over and Canada's inaugural Food and Drugs Act was passed in 1920, regulation went dark. Manufacturers and pharmacies found to have adulterated products were no longer publicly identified unless the case went to court, which seldom occurred. When the department began collecting evidence about drug safety in the 1940s and '50s (including drug effectiveness in the later decade), it treated that information as company property, not to be shared. .,3 $^{3}$

Fast-forward to the present and it's clear that this institutionalized practice of secrecy has not served the public well: physicians have been misinformed and patients have been unnecessarily harmed. ${ }^{4}$ For example, tens of thousands of people are estimated to have died from cardiac arrest after being prescribed the arthritis medication rofe-

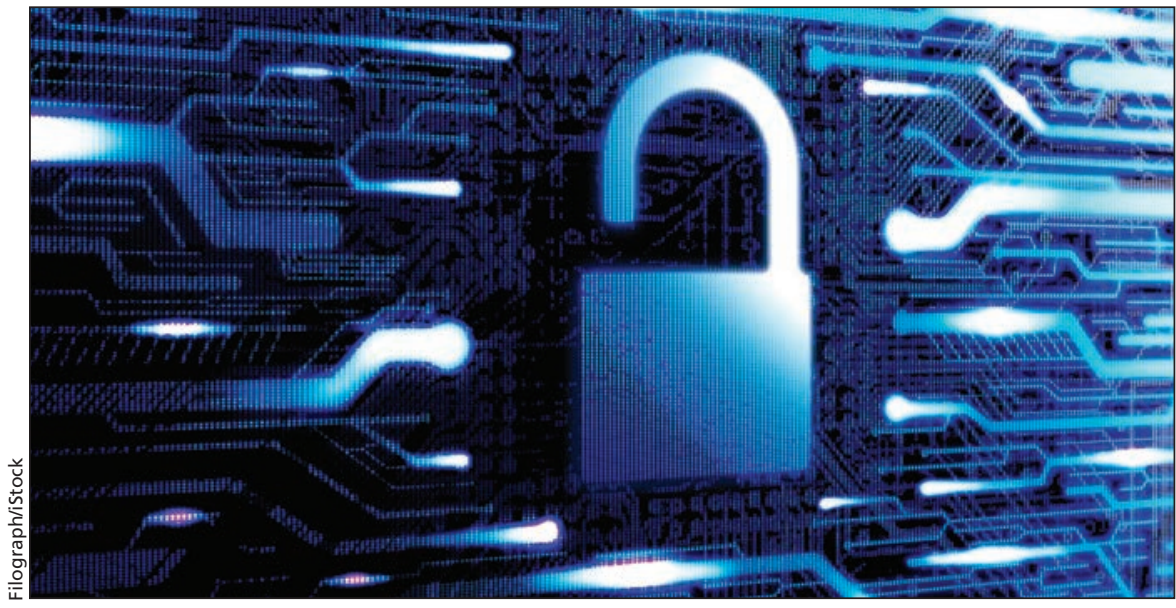

coxib $(\text { Vioxx })^{5}-$ a risk that regulatory officials had previous knowledge of but nevertheless kept confidential.

Parliament's passage of Bill C-17, "Vanessa's Law," in 2014 may finally mark the beginning of change. Inspired by the death of MP Terence Young's daughter, Vanessa, from an adverse drug event in 2000 , the law created new and important legislative powers, including some related to transparency. Canada's minister of health now has explicit discretion to release drug safety and effectiveness data. Vanessa's Law also imposed a requirement on drug manufacturers to make public certain "prescribed information." But the question remains: How well will the regulator exercise this discretion and define what "prescribed information" must be shared given the entrenched practice of deferring to company assertions that drug safety and effectiveness information is company property?

Although Vanessa's Law created new transparency powers, it also legitimated Health Canada's long-standing practice of treating drug safety and effectiveness information as proprietary. The definition of "confidential business information" in the legislation can accommodate drug safety and effectiveness data provided that the data are not publicly avail- able; that the drug company has taken steps to keep the data confidential; and that the data have some actual or potential economic value, which any clinical information has if it sheds light on a drug's safety or effectiveness.

However, just as Vanessa's Law reified drug safety and effectiveness data as confidential business information, it also gave Health Canada the permission to do what it hasn't - rightly or wrongly - believed it had the legal authority to do: disclose confidential business information. For example, under section 21.1(2), the minister may disclose confidential business information without the drug maker's prior consent if he or she "believes that the product may present a serious risk of injury to human health."

Therein lies both the promise and the challenge of reinstitutionalizing transparency in Canadian drug regulation. On the one hand, the new law's provisions take advantage of Health Canada's established institutional grammar, giving the regulator licence to make data available where it didn't before. Empowering the regulator to disclose confidential business information offers a solution that is easier to implement than removing drug safety and effectiveness data from the category of confidential business information and requiring the regu- 
lator to create new procedures to segregate and store information differently depending on its proprietary status.

On the other hand, there's reason to doubt genuine change will follow the enactment of Vanessa's Law. Health Canada's culture of secrecy may limit the minister's willingness to use these new discretionary powers of transparency. Further, what procedures will Health Canada follow before invoking its authority to disclose confidential business information? Will the regulator have a back-and-forth with the implicated drug company before releasing data? What if the company objects to the disclosure? Will that limit or delay access? What strings will Health Canada attach to any data it discloses?

\section{Campaign for change}

The history of drug regulation shows that changing Health Canada's institutional practices will require more than a change in the law. The practice of publishing bulletins ended (1920) long before the regulator's legislative authority to publish them was taken away (1953). Law and practice thus exist in a complex dialogue, at times broken, and always subject to social influence.

Consider the factors behind the regulatory shift from transparency to secrecy through the early to mid-20th century. First, industry rallied against the negative publicity generated by the regulator's bulletins. ${ }^{2}$ According to one civil servant, it was clear that " $[\mathrm{t}]$ he new Department into whose hands control of the laboratories had passed, was not impressed with the advantages of publicity." ${ }^{2}$ Second, industry's influence over regulatory decisionmaking increased throughout the 20th century. ${ }^{1}$ Once the Department of Health was formed, industry became directly involved in drafting regulations and developing guidelines and other materials. $^{2}$ The regulator assumed a cooperative approach with industry on the theory that this was the more effective means of regulation, ${ }^{6}$ reinforced through a revolving door of employees between industry and the regulator. ${ }^{1,7}$ Third, as early as the 1940s, Canadian regulatory officials began interacting with their American counterparts, embracing the norms of confidentiality that dictated American regulatory practice. ${ }^{1}$ Fourth, norms within the profession of medicine shifted substantially. Throughout the 19th century, the profession was a vocal critic of intellectual property generally, and secrecy especially, within the drug trade. ${ }^{8}$ This informed the regulator's early commitment to transparency. However, during the 20th century, medicine came to regard so-called ethical drug manufacturers favourably. This segment of the drug industry eschewed the absolute secrecy of quack medicine makers only to embrace sharing, in strict confidence, evidence of a drug's safety and effectiveness with regulators to secure market approval from the 1940s forwards. As that segment of the industry became the Big Pharma of today, the medical profession's once vocal criticism of industrydriven secrecy diminished, leaving the regulator without an ally in transparency.

Medicine's move to the background amidst the regulator's acceptance of industry's proprietary claims attests not only to the social character of law but also a strategy for institutional change anew. For, if the shared silence of physicians and biomedical researchers helped precipitate the status quo, then their collective disquiet has the potential to be disruptive. Several individual physician researchers, including, among others, Sir Iain Chalmers, Marcia Angell, Joel Lexchin, Peter Gøtzsche, Tom Jefferson and Ben Goldacre, have led the call for greater transparency in pharmaceutical research and regulation. To fundamentally alter Health Canada's practices and substantially improve the regulation of pharmaceuticals, the work of these individuals must scale up.

One simple yet powerful way to begin is to file a new kind of request for information that Health Canada is now legally empowered to entertain. Specifically, under section 21.1(3) of Vanessa's Law, the minister of health can disclose confidential business information if its purpose is "related to the protection or promotion of human health or the safety of the public" and provided the disclosure is to "a person who carries out functions relating to the protection or promotion of human health or the safety of the public." That provision should include physicians who have prescribed or intend to prescribe a medication and want to ensure that they as well as their patients are fully apprised of all the drug's potential risks and benefits. It should also extend to any researcher (physician or otherwise) whose research evaluates the potential risks and benefits of a drug, and to consumer protection organizations with a genuine interest in alerting the public about the potential risks and benefits of a drug.

To help achieve actual change to Health Canada's practices, the biomedical community should demand information to guide pharmaceutical prescribing and research. One physician has done so, but the terms of data access set by Health Canada raise important concerns about the physician's ability to complete his work and share his findings with researchers and patients. ${ }^{9,10}$ Help set a better precedent: Write to the minister of health to request drug safety and effectiveness data from Health Canada; push the regulator for better terms of access to enable meaningful, independent scrutiny of pharmaceutical data and help motivate institutional change.

\section{Matthew Herder LLM JSM}

Health Law Institute, Dalhousie University, Halifax, NS

\section{References}

1. Herder M. Denaturalizing transparency in drug regulation. McGill Journal of Law \& Health 2015; 8:S57-143

2. Davidson AL. The genesis and growth of food and drug administration in Canada. Ottawa: Department of National Health and Welfare; 1949.

3. Lexchin J, Mintzes B. Transparency in drug regulation: Mirage or oasis? CMAJ 2004;171:1363-5.

4. Gøtzsche PC. Why we need easy access to all data from all clinical trials and how to accomplish it. Trials 2011;12:249.

5. Graham DJ, Campen D, Hui R, et al. Risk of acute myocardial infarction and sudden cardiac death in patients treated with cyclo-oxygenase 2 selective and non-selective non-steroidal anti-inflammatory drugs: nested case-control study. Lancet 2005;365:475-81.

6. Curran RE. Canada's food and drug laws. Chicago: Commerce Clearing House; 1953.

7. Lexchin J. Health Canada and the pharmaceutical industry: a preliminary analysis of the historical relationship. Healthc Policy 2013;9:22-9.

8. Swanson KW. Food and drug law as intellectual property law: historical reflections. Wisc L Rev 2011;329.

9. Bruser D, McLean J. Toronto doctor muzzled, not allowed to talk about morning sickness drug info. The Toronto Star 2015 Oct. 14. Available: www.thestar .com/news/canada/2015/10/14/health-canada-hands -over-documents-but-muzzles-doctor.html (accessed 2015 Oct. 20)

10. Herder M, Lemmens T. Diclectin data: testing Canada's new pharmaceutical transparency law. BMJ Blogs 2015 Oct. 27. Available: http://blogs. bmj.com/bmj/2015/10/27/diclectin-data-testing -canadas-new-pharmaceutical-transparency-law (accessed 2015 Nov. 5).

This article has been peer reviewed.

CMAJ 2016. DOI:10.1503/cmaj.150765 